\title{
Você pediu, a USS atendeu: Feedback da avaliação institucional
}

\author{
You asked, The USS Attended: Feedback from Institutional Evaluation Assessment
}

\author{
Claudenir Pereira do Val ${ }^{\dagger *}$; Jonas dos Santos Pacheco; César da Conceição Simões\$; Magda Vieira \\ Barbosal"; Sileno Corrêa Brum ${ }^{\circ}$; Tânia Maria Machado Pinto ${ }^{\square}$ Luiz Felipe Caramez Berteges ${ }^{\bullet}$
}

\begin{abstract}
Resumo
Como citar esse artigo. do Val, C.P.; Pacheco, J.S.; Simões, C.C.; Barbosa, M.V.; Brum, S.C.; Pinto, T.M.M.; Berteges, L.F.C. Você pediu, a USS atendeu: Feedback da avaliação institucional. Revista

Atividades de extensão são compostas por projetos e ações. Estas últimas compreendem marcos planejados e atingidos, dentro do contexto mais amplo dos projetos. O presente artigo pretende relatar a experiência da Comissão Própria de Avaliação(CPA) da Universidade Severino Sombra (USS), ao desenvolver uma ação informativa, divulgada como: "Você pediu a USS atendeu: Feedback da Avaliação Institucional”. O objetivo principal da atividade foi demonstrar aos alunos, professores, funcionários e comunidade em geral, através de uma ação de informação, as mudanças efetivas no contexto acadêmico para cada curso de graduação, ressaltando a importância da participação dos alunos e professores nas referidas ações da CPA. As mudanças registradas se originam das melhorias proporcionadas, advindas dos relatórios de Avaliação Institucional elaborados pela CPA. Neste sentido, podemos afirmar que a busca pela cultura de feedback da avaliação tem sido fortalecida e aos poucos consolidada, atendendo a uma das premissas da CPA e, por consequência, aumentando também, a credibilidade do trabalho realizado. O referido evento proporcionou à comunidade acadêmica discente $\mathrm{e}$ docente uma maior participação nos processos de tomada de decisão da equipe gestora da Instituição. Palavras-Chave: Avaliação Institucional; Educação Superior; Ação Informativa; Melhoria Contínua.
\end{abstract}

\begin{abstract}
Educational extension projects are composed by projects and actions. The latter includes milestones that are planned and achieved within the ampler spectrum of the project. This article aimed at describing the committee for assessment - CPA at University Severino Sombra (USS), who developed an event, published as: "You asked, USS answered: Feedback on Institutional Evaluation". The main objective of the activity was to demonstrate to students, faculty, staff and community in general, through an information event the actual changes in the academic context for each undergraduate course, emphasizing the importance of the participation of students and teachers in the actions of the CPA. The recorded changes stem from proportionate improvements through the Institutional Evaluation reports by the CPA. In this sense, we can say that the search for the evaluation of feedback culture has been strengthened and gradually consolidated, serving one of the premises of the CPA and therefore also increasing the credibility of the work done. That event provided the academic community with greater participation on the decision-making processes of Institutional Management. Keywords: Institutional Evaluation; Higher Education; Continuous Improvement; USS.
\end{abstract}

\section{Introdução}

Em função da importância do processo de avaliação para a instituição, no que diz respeito à busca constante de um ensino de qualidade, torna-se necessário o envolvimento dos atores institucionais nesta missão, dando-lhe a oportunidade de participar diretamente deste processo, pois "a prática da autoavaliação como processo permanente será instrumento de construção e/ou consolidação de uma cultura de avaliação da instituição, com a qual a comunidade interna se identifique e comprometa". (ABMES, 2004)

Opresente trabalho tem como objetivo principal demonstrar as ações de melhorias realizadas na USS, oriundas da avaliação institucional e dos cursos de graduação nos últimos dois anos, como estratégia de informar àqueles que, direta ou indiretamente, auxiliaram e participaram do processo avaliativo através do portal da USS, interferindo para seu engrandecimento. Considerou-se também alguns objetivos específicos que são: garantir retorno

Afiliação dos autores: † Coordenadora da CPA-USS; Professora Assistente II da Universidade Severino Sombra, Curso de Administração;

\$ Membro da CPA-USS; Professor Assistente II da Universidade Severino Sombra, Cursos: Engenharia Ambiental, Engenharia Elétrica, Engenharia de Produção;

$\S$ Membro da CPA-USS; Professor Assistente II da Universidade Severino Sombra, Cursos: Engenharia Civil, Engenharia Elétrica, Engenharia de Produção;

|| Membro da CPA-USS; Professora Assistente I da Universidade Severino Sombra, Curso de Enfermagem;

O Membro da CPA-USS; Professor Adjunto I da Universidade Severino Sombra, Curso de Odontologia;

$\square$ Membro da CPA-USS; Professora Assistente II da Universidade Severino Sombra, Curso de Pedagogia;

- Membro da CPA-USS; Professor Assistente II da Universidade Severino Sombra, Curso de Engenharia de Produção.

*claudenir.val@gmail.com, 
sobre as informações recebidas, computadas e avaliadas através das pesquisas realizadas pela CPA, disponibilizando informações e dados para o conhecimento da comunidade acadêmica; ampliar a cultura de avaliação institucional no corpo discente e docente, integrando-os com as posturas desenvolvidas pelo setor, oportunizando a reorganização e a melhoria dos serviços prestados até então; fortalecer e consolidar a cultura de feedback da avaliação na USS; proporcionar maior credibilidade ao trabalho realizado pela CPA; dar ampla divulgação às atividades desenvolvidas pela CPA, no âmbito dos segmentos a que representam, ou seja, corpo discente, corpo docente, funcionários e sociedade civil organizada.

Pode-se afirmar que a atividade desenvolvida se justifica, em função de oferecer, para aqueles que colaboraram com a CPA, respondendo aos instrumentos de coleta de informações na avaliação de cursos e avaliação institucional, as soluções, as informações e as possíveis sugestões, elementos considerados fundamentais, que proporcionam a melhoria contínua da USS.

Outro ponto de fundamental importância, é que a elaboração do referido projeto possa servir de motivação para aqueles que, ao conhecerem os resultados do trabalho, se interessem em participar da rotina de avaliação, integrando em sua vida acadêmica a cultura do processo avaliativo institucional. Nessa perspectiva, possibilita a CPA mediar a estruturação de novas propostas e reestruturar posicionamentos para que a IES (Instituição de Ensino Superior) atenda às necessidades e atue mais próximo da realidade $\mathrm{e}$ dos interesses de seus alunos e professores, visto que os indicadores de perfis propostos nos instrumentos avaliativos apontam e evidenciam o sentido de possível aprimoramento do trabalho através do feedback da CPA.

Neste contexto, a CPA-USS tem como premissa a consolidação de uma cultura avaliativa, em atendimento ao que prevê o Ministério da Educação e Cultura - MEC, através da Lei 10.861, de 14 de abril de 2004, instituída pelo Sistema Nacional de Avaliação da Educação Superior - SINAES, buscando uma prática consciente e contínua com o envolvimento da comunidade acadêmica.

Ressaltamos, que a elaboração do referido projeto atende a uma das atribuições da CPA, que é informar a seu público alvo quais situações foram sinalizadas na autoavaliação e que providências foram tomadas sobre as questões levantadas. É importante enfatizar que, nesse processo, o princípio da transparência é predominante no modelo de gestão que, não só a CPA adota, como também a instituição como um todo.

\section{Avaliação na USS: histórico e evolução}

Neste item, faremos a descrição sumária do histórico do processo de autoavaliação realizado na USS, bem como sua evolução. O processo de autoavaliação na USS teve início em 1998, com a constituição da Coordenadoria de Avaliação Institucional, de acordo com a Portaria $\mathrm{n}^{\mathrm{o}}$ 01/98 da Reitoria. Inicialmente o processo era realizado manualmente e mais tarde passou a ser informatizado. A partir de então, alunos, professores e funcionários passaram a realizar as avaliações através de um sistema próprio, desenvolvido pela área de tecnologia da informação da instituição. A implementação desta ferramenta, tornou o processo de avaliação mais confiável e rápido. A tabulação dos dados passou a ser realizada com mais agilidade e a emissão dos relatórios da avaliação repassados aos gestores com menor espaço de tempo, tornando o feedback mais eficaz. Com base nesses relatórios, os planos de ação eram formulados, tendo como referência as fragilidades e sugestões apontadas e as providências a respeito tomadas. $\mathrm{O}$ processo de avaliação se manteve nesses moldes até 2003, passando por diversas adaptações e melhorias contínuas. No ano de 2004, com a Lei do SINAES (BRASIL, 2004), o processo de avaliação interna passou a ser realizado pela CPA, que fora constituída a partir de então, pois "cada instituição de ensino superior, pública ou privada, constituirá Comissão Própria de Avaliação - CPA, no prazo de 60 (sessenta) dias, a contar da publicação desta Lei” (Art. 11).

No decorrer dos anos, o processo de avaliação passou por diversas mudanças, a equipe da CPA buscou o envolvimento de alunos, professores e funcionários.

Com o objetivo de explicitar as práticas de autoavaliação na USS, elencamos a seguir algumas ações realizadas: reestruturação do setor com a criação da identificação do mesmo através da logomarca da avaliação, com o objetivo de caracterizar a CPA e proporcionar maior visibilidade ao setor; divulgação acirrada dos processos de avaliação: elaboração de material gráfico - banner, cartaz, filipeta e camisa; postagens no site da USS; criação da página da CPA no Facebook; envio de e-mail aos coordenadores e representantes de turma; consolidação de colegiados de cursos de graduação, com participação de alunos; desenvolvimento de ações estratégicas como concurso de frases, gincanas, workshops, com oobjetivo de envolver alunos e professores e incentivar a prática consciente e continuada da avaliação; criação do Selo da CPA, que foi elaborado com o objetivo de identificar as ações realizadas na 
USS e que foram oriundas das avaliações internas e externas. Tal iniciativa demonstra a preocupação da CPA em proporcionar à comunidade acadêmica (alunos, professores e funcionários) o retorno das sinalizações por eles realizadas, assim como à sociedade de modo geral, reforçando a cultura de feedback da avaliação; organização de reuniões com os representantes discentes dos Centros Acadêmicos, Diretório Central de Estudantes e representantes de turma dos diversos cursos de graduação, para divulgação, orientação e conscientização do processo de avaliação; realização do "Dia Especial da Avaliação", evento realizado no primeiro dia do início do processo de avaliação, quando são entregues filipetas de divulgação, envolvendo alunos e professores dos diversos cursos de graduação, vespertinos e noturnos, no Campus universitário e também abrangendo os funcionários nas áreas administrativas, dependências do HUV (Hospital Universitário de Vassouras), Colégio de Aplicação, Casa de Memórias Severino Sombra, Serviço-Escola de Psicologia e Unidade Experimental Prof. Antonio Orlando Izolani (Hospital Veterinário - Sítio dos Barreiros).

Ressaltamos que o trabalho realizado pela CPAUSS, através das ações e estratégias desenvolvidas, pode ser avaliado em função do crescimento de seu conceito nas avaliações in loco do MEC, no período de quatro anos, conforme demonstrado no Quadro 1 :

Quadro 1. Conceito da CPA-USS nas avaliações in loco, dos cursos de graduação, no período de 2012 a 2015.

\begin{tabular}{ccc}
\hline Curso & Conceito & Ano \\
\hline Engenharia de Produção & 3 & 2012 \\
\hline Farmácia & 3 & 2013 \\
Medicina & 5 & 2013 \\
História & 4 & 2014 \\
Gestão Pública & 5 & 2015 \\
\hline
\end{tabular}

\section{Metodologia}

O projeto em questão caracteriza-se por ter uma abordagem qualitativa e descritiva, com o objetivo de informar, tornar público e registrar o trabalho desenvolvido pela CPA, no que tange às ações de melhorias realizadas na USS, conscientizando os alunos da importância de sua participação na avaliação institucional.

Para corroborar a afirmativa acima, tomemos o trecho de Minayo (1995, p. 87):

"A pesquisa qualitativa responde a questões muito
particulares. Ela se preocupa nas ciências sociais, com
um nível de realidade que não pode ser quantificado,
ou seja, ela trabalha com o universo de significados,
motivos, aspirações, crenças, valores e atitudes, o
que corresponde a um espaço mais profundo das
relações dos processos e dos fenômenos que não
podem ser reduzidos à operacionalização de variáveis."

A proposta do projeto foi construída a partir de reuniões e discussões com os membros da CPA-USS e foi estruturada nas seguintes etapas: a) reuniões com representações de alunos para apresentação do projeto; b) confecção de um informativo com as ações de melhorias ocorridas nos cursos e na USS, em tamanho A4, com quatro folhas e oito laudas de conteúdo, para distribuição entre alunos e professores; c) confecção de um banner no tamanho $6 \mathrm{~m} \times 2 \mathrm{~m}$ e três no tamanho $1,20 \mathrm{~m} \times 0,80 \mathrm{~m}$, que foram afixados em locais estratégicos no campus universitário. O informativo digital foi divulgado também no site institucional, na página do Facebook da CPA e da USS; d) ação informativa: visitas as salas de aula para informação direta do projeto; e) análises e discussões sobre o projeto. A ação informativa foi realizada após o término do período destinado a participação na avaliação dos cursos. Em seguida, o período de avaliação foi prorrogado, a fim de que pudesse ser feita a análise do impacto do projeto nas avaliações. Na Figura 1, segue uma representação da metodologia empregada: 


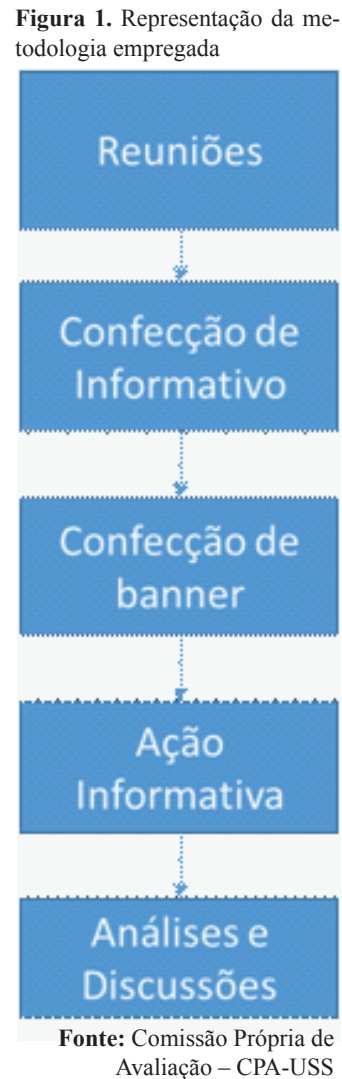

\section{Resultados e discussões}

Após o término do período de participação dos alunos na avaliação institucional a ação do projeto foi colocada em prática. O evento contou com a participação direta de 3.040 pessoas, sendo 2.750 alunos, 270 professores, 20 membros da CPA-USS. Os membros voluntários da CPA organizaram-se em duplas e foram visitando as salas de aula até que todas tivessem sido visitadas, passando a informação do que se tratava o projeto e distribuindo folhetos. Vale ressaltar que a abrangência da divulgação obteve uma proporção maior, considerando que o projeto foi divulgado nas mídias sociais, conforme mencionado anteriormente. $\mathrm{O}$ evento ocorreu no dia 02 de junho de 2016.

A equipe da CPA realizou ação no sentido de abordar os 15 cursos, sendo: Administração, Enfermagem, Engenharia Ambiental, Engenharia Civil, Engenharia da Computação, Engenharia de Produção, Engenharia Elétrica, Engenharia Química, Farmácia, Fisioterapia, Pedagogia, Psicologia, Odontologia, Veterinária e Medicina. Após o evento a data para preenchimento do formulário foi prorrogada por mais uma semana para que os alunos que não haviam participado pudessem participar da avaliação. O Gráfico 1, mostra o aumento de participação dos alunos por curso.

Foi possível observar que, com exceção do curso de Farmácia, todos os outros cursos tiveram
Gráfico 1. Participação de alunos na avaliação dos cursos Participação dos Cursos

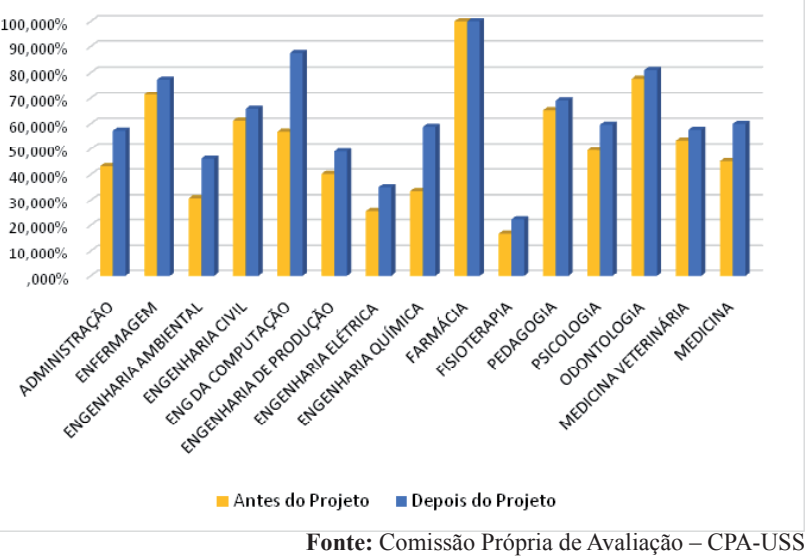

aumento considerável na participação da avaliação após a divulgação do projeto. Os cursos com melhores participações foram os cursos de Enfermagem, Engenharia da Computação, Odontologia e Farmácia, todos acima de $70 \%$ de participação.

O curso de Farmácia foi o único curso que já havia tido uma participação de $100 \%$ dos alunos na avaliação, antes mesmo do evento do projeto. Este fato é interessante pois o curso de Farmácia está em suas últimas turmas, pois há alguns anos a universidade não abre mais turmas e o curso está para ser fechado.

No intuito de melhorar a participação geral dos alunos nas avaliações futuras os cursos com maior oportunidade de melhoria são os cursos de Engenharia Ambiental, Engenharia de Produção, Engenharia Elétrica e Fisioterapia, onde não passaram de $50 \%$ de participação na avaliação.

Os demais cursos mostraram um aumento significativo após o evento e a prorrogação da avaliação. No Gráfico 2, segue o demonstrativo

Gráfico 2. Aumento de participação de alunos na avaliação pós-evento

\section{Aumento de Participação pós Evento}

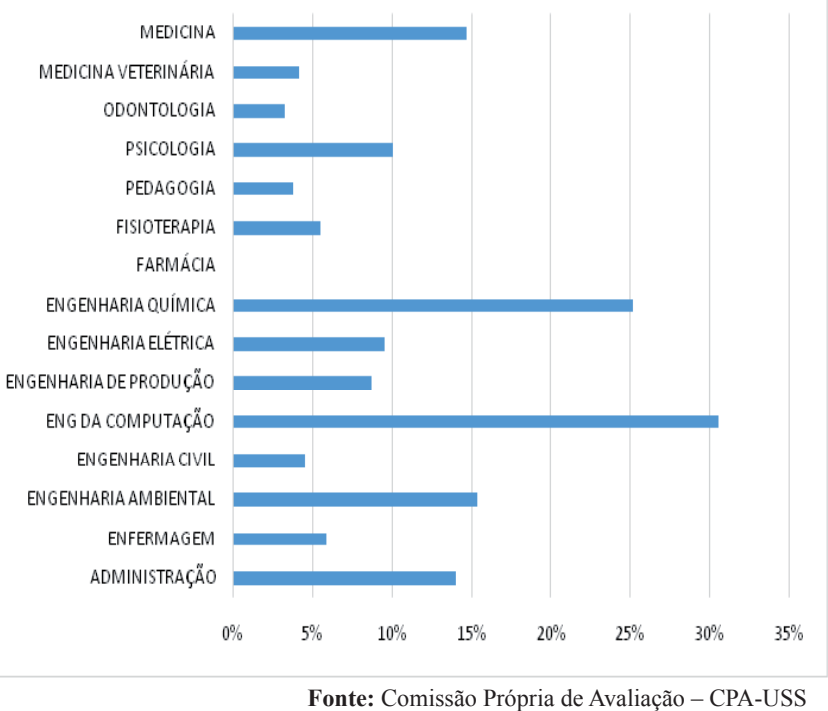


desse aumento.

Com exceção do curso de Farmácia, que já havia tido uma participação de $100 \%$ na avaliação, os cursos com menor aumento na participação foram os cursos de: Medicina Veterinária, Odontologia, Pedagogia e Engenharia Civil ficando abaixo de 5\% de aumento das participações. Os cursos matutinos tiveram um menor aumento na participação, provavelmente pelo fato do evento ter ocorrido à noite e tais cursos terem recebido a informação somente por meios indiretos de banner, folders e folhetos espalhados pela instituição. O curso de Medicina mostrou um aumento significativo, pois além dos meios indiretos, uma reunião foi agendada com os representantes de turmas para relatar o projeto e a partir destes a informação foi difundida. Já os cursos de Pedagogia e Engenharia Civil merecem uma atenção melhor para futuros projetos, pois mesmo com o evento e com todos os incentivos o aumento de participação não foi significativo.

No Gráfico 3, pode-se observar esse aumento em comparação com o período anterior, onde a primeira coluna mostra a participação geral em 2015-2, a segunda a participação de 2016-1 antes do projeto e a participação geral em 2016-1 após o projeto.

Gráfico 3. Comparativo de participação na avaliação

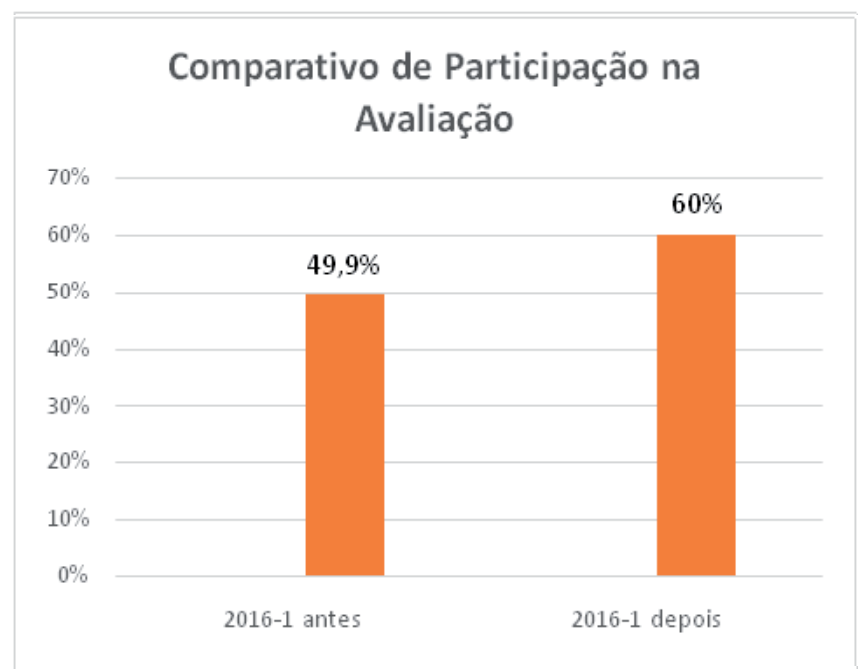

Fonte: Comissão Própria de Avaliação - CPA-USS

Nesse sentido, a CPA incentiva e contribui para a consolidação da cultura de feedback do processo de avaliação na IES. De uma forma geral, o projeto se mostrou de grande valia, pois o aumento da participação foi relevante e, com isso, houve um ganho para a instituição; com mais informação a chance de atender às necessidades dos alunos aumenta, melhorando, assim, os serviços prestados pela Universidade, sempre visando a melhoria contínua.

A realização do evento impactou positivamente no percentual de participação de alunos na avaliação dos cursos, conforme demonstrado no Gráfico 4:

Gráfico 4. Participação de alunos em 2015-2 e 2016-1

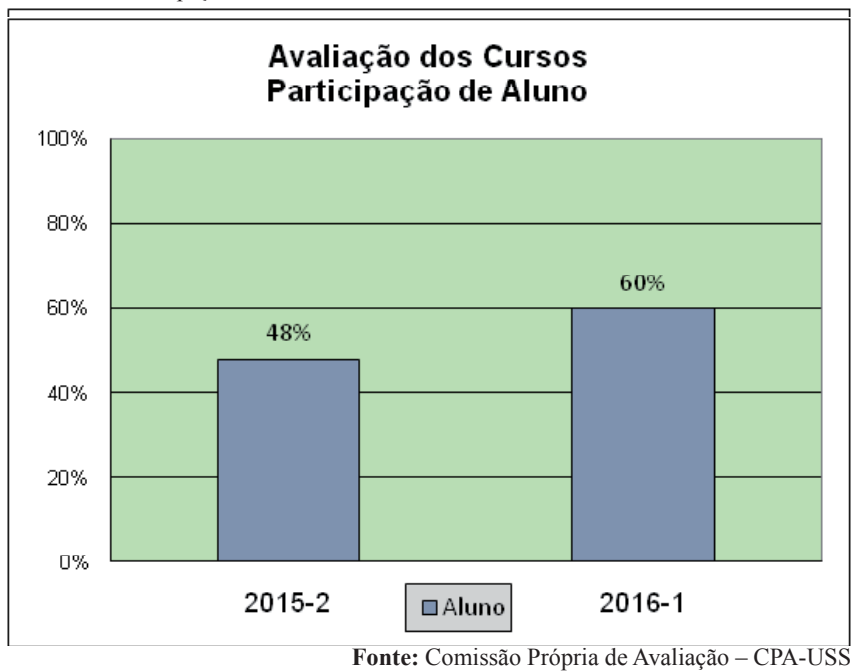

O evento teve um potencial de sensibilização considerado expressivo, pois com a intervenção direta em sala dos diferentes cursos foi possível demonstrar aos alunos o real cumprimento da função da Comissão Própria de Avaliação.

Em relação ao desempenho dos alunos durante as abordagens em sala de aula pôde-se observar que estes já conheciam o processo de avaliação, porém não percebiam, até então, que suas solicitações eram atendidas por intermédio da CPA. Dessa maneira, os alunos puderam compreender melhor a importância da participação nas avaliações dos cursos.

Tal fato teve impacto sobre os alunos que, por sua vez, aumentaram o número de participação nas avaliações.

\section{Conclusão}

Diante do exposto, concluímos que o evento atingiu seus objetivos, por envolver discentes, docentes e equipe gestora, além de ter possibilitado crescimento e avanços no processo de tomadas de decisão da equipe gestora com base na discussão e apresentação direta das propostas dos alunos, através da realização do Projeto "Você pediu a USS Atendeu'.

O fator em destaque é referente ao crescente interesse dos alunos em participar de tal ação em relação ao ano anterior, fato este gratificante para a equipe da CPA, visto que as metas e a credibilidade do setor estão sendo atingidas, principalmente em relação ao envolvimento do alunado no processo avaliativo no ensino superior na IES.

Conclui-de, assim, que a ação informativa promovida pela CPA favoreceu a aquisição de 
conhecimentos sobre a avaliação institucional, incluindo a relevância social através das atividades realizadas entre os cursos, onde as práticas competitivas estimulam comparações entre os desiguais com o foco pedagógico e de solidariedade humana.

\section{Referências}

ASSOCIAÇÃO BRASILEIRA DE MANTENEDORAS DE ENSINO SUPERIOR - ABMES.Caderno 12, 2004.

BRASIL. Lei $\mathrm{n}^{\circ} .10 .861$, de 14 de abril de 2004. Sistema Nacional de Avaliação da Educação Superior - SINAES. Brasília, DF, 15 abr. 2004.

\section{Nota Técnica INEP/DAES/CONAES nº 065. 2014.}

MINAYO, M. C. S. O desafio do conhecimento: pesquisa qualitativa em saúde. 8. ed. São Paulo: Hucitec, 1995.

UNIVERSIDADE SEVERINO SOMBRA - USS. Relatório de Avaliação Institucional da CPA, 2015. 